\title{
Resistivity measured by direct and alternating current: why are they different?
}

\author{
V. Y. Zadorozhnaya \\ Council for Geoscience, 280 Pretoria str., Pretoria, 0184, South Africa
}

Received: 26 July 2008 - Revised: 4 November 2008 - Accepted: 5 November 2008 - Published: 14 November 2008

\begin{abstract}
Mathematical modeling of a little known model of IP referred to as "induced polarization caused by constrictivity of pores" was developed. Polarization occurs in all types of rocks if surface areas and transfer numbers are different for connected pores. The duration of the polarization process depends on two parameters: pore radii of connected capillaries and transfer numbers. During the polarization process all contacts between pores of different transfer numbers will be blocked and the electrical current will flow through the remaining canals. Two phenomena control the amplitude of potential difference at time-on: 1 . Successive blockage of pores increases the resistivity of sediments and results in increased measured potential difference. 2. Excess concentration of electrolyte at the boundaries between pores with different radii provides an additional potential. The amplitude of the potential difference (voltage) of such rocks not only depends on solutions filling pore spaces, porosity and tourtuosity of pores channels, but also on ion mobility, diffusion coefficient, and difference of transfer numbers. During timeon a voltage is occurred due to flowing current $U_{\text {curr }}(t)$ and excess concentration $U_{\text {excess }}(t)$ at the contacts. However during the time-off only the excess of concentration $U_{\text {excess }}(t)$ is involved in the diffusion process which tends to level the ion concentration along the pores. It was found that the measured chargeability is proportional to the porosity. Blockage of pores and excess/loss ions at the contacted pores control this physical parameter.

However the relationship between resistivity and porosity is very complicated. Mathematical modeling and laboratory measurements both confirmed the membrane IP effect diminishing with increasing salinity of fluid filled pores of rocks. Membrane polarization does not exist on high frequency of electrical current. As a result the resistivity mea-
\end{abstract}

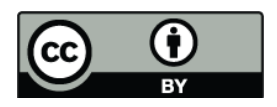

Correspondence to: V. Y. Zadorozhnaya (valeriya@geoscience.org.za) sured by direct and alternating current is different. The new algorithm was tested on laboratory measurements data showing its good agreement with theory. The calculation of pore size distribution using IP laboratory data has been presented. The definition of the membrane IP effect is: "Membrane IP is the successive blockage of inter-pore connections due to the excess distribution of ions during current flow".

\section{Introduction}

It is known that resistivity measured by direct and alternating current is different. This is caused by a phenomenon of induced polarization occurring in the rocks. Two slow types of induced polarization (IP), namely electrode and membrane polarization are known and accepted worldwide. The model of membrane induced polarization (diffusion coupling) was proposed by Marshal and Madden (1959). It was shown that the diffusion gradients and the electrical potential gradient had to be considered as primary driving forces for the ion motion.

Keller (1959), Keller and Licastro (1959) have proposed the concept of ion traps to explain polarization in claybearing rocks - membrane polarization. According to numerous publications membrane polarization arises chiefly in porous rocks in which clay particles partially block ionic solution paths. The diffused cloud of cations (double layer) in the vicinity of a clay surface is characteristic of a clayelectrolyte system (Ward, 1990). Under the influence of an electric field, positive charges (cations) easily pass through the cationic cloud but negative charges accumulate. The clay particles and their immediate vicinity acts as an ion-selective membrane: it is a barrier to ions. Upon elimination of the electric field, all charges return to equilibrium positions by a diffusion process. The ion mobility reduction has a stronger influence for slow potential variations (for example $0.1 \mathrm{~Hz}$ ),

Published by Copernicus Publications on behalf of the European Geosciences Union. 

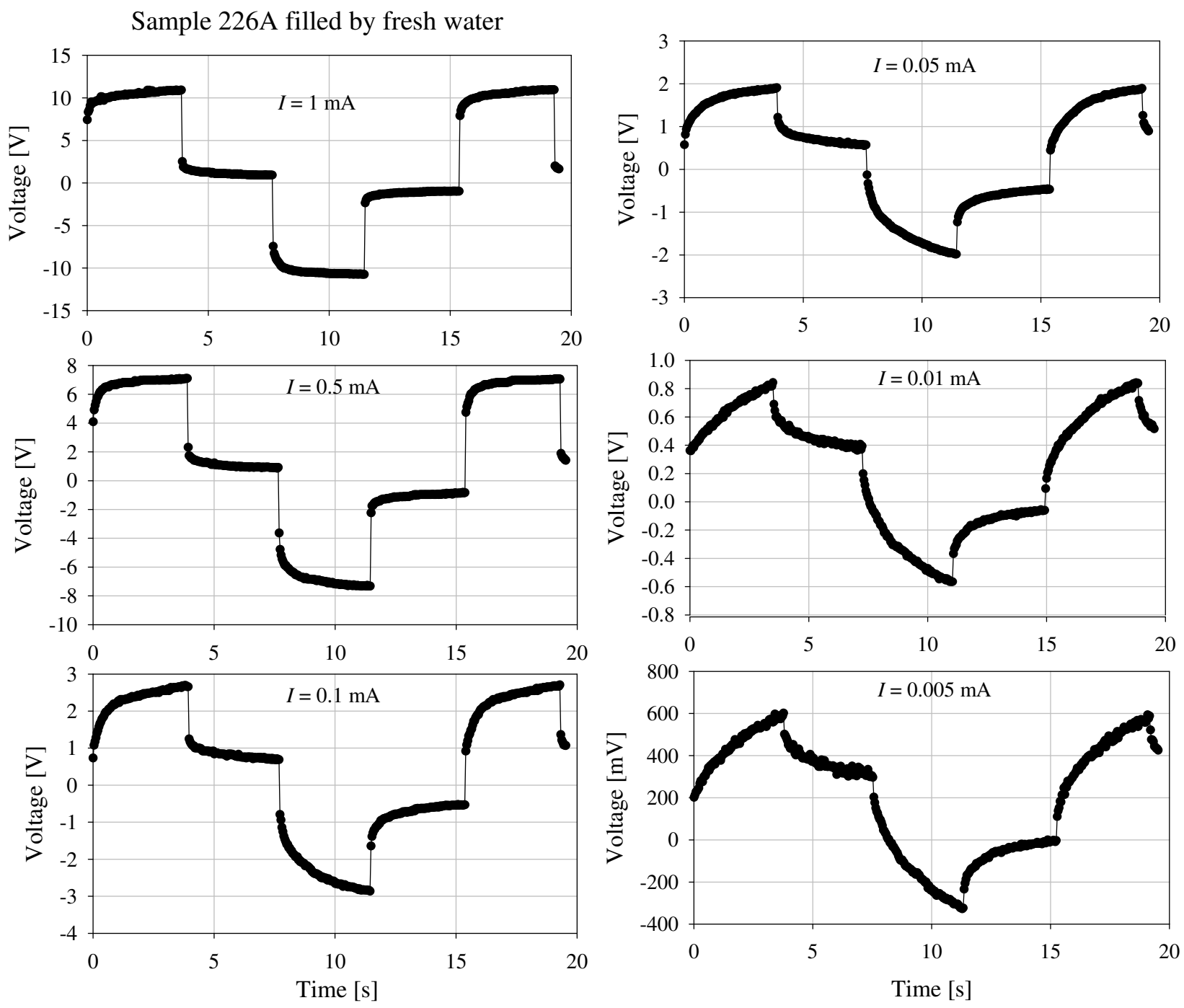

Fig. 1. Laboratory measurements of sandstone 226A filled by fresh water.

related to the time of diffusion of ions between adjacent membrane zones.

Following from Jost (1952), Anderson and Keller (1964) who were the first to use the applied diffusion (heat) equation to explain the phenomenon of membrane polarization in the rocks it was found that the diffusion of ions through the pores of rocks was presented as diffusion through a half limited capillary tube. This simplifies the equation to a homogeneous diffusion equation (at time-off) with boundary and initial conditions:

$C(x, t)=C_{0}$ at $\quad t=0, x=0$,

$C(x, t)=0$, for all $x$ at $t \gg 0$

To the following:

$C(x, t)=\frac{C_{0}}{2}\left[1-\operatorname{erf}\left(\frac{x}{2 \sqrt{D t}}\right)\right]$ where $C(x, t)$ is the increase above normal concentration written as a function of the variable $x$ and $t, x$ being the distance of concentration build-up in the direction of diffusion, and $t$ is elapsed time from the instant the ions start diffusing, $C_{0}$ is the initial excess of concentration where the ions have accumulated, $D$ is the diffusion coefficient. Let us follow these authors and write the decision of diffusion equation at time-on with initial and boundary conditions:

$$
\begin{aligned}
& C(x, t)=0 \text { at } t=0, x=0, \\
& C(x, t)=0, \text { for all } t \text { for } \quad x \gg 0
\end{aligned}
$$

This is equal to (Koshlyakov, et al., 1970):

$C(x, t)=\frac{C_{0}}{2}\left[\operatorname{erf}\left(\frac{x}{2 \sqrt{D t}}\right)\right]$

Therefore Eq. (2a) is equal to Eq. (2b), taking into account opposite time elapsed. Take note that the model of sediments 


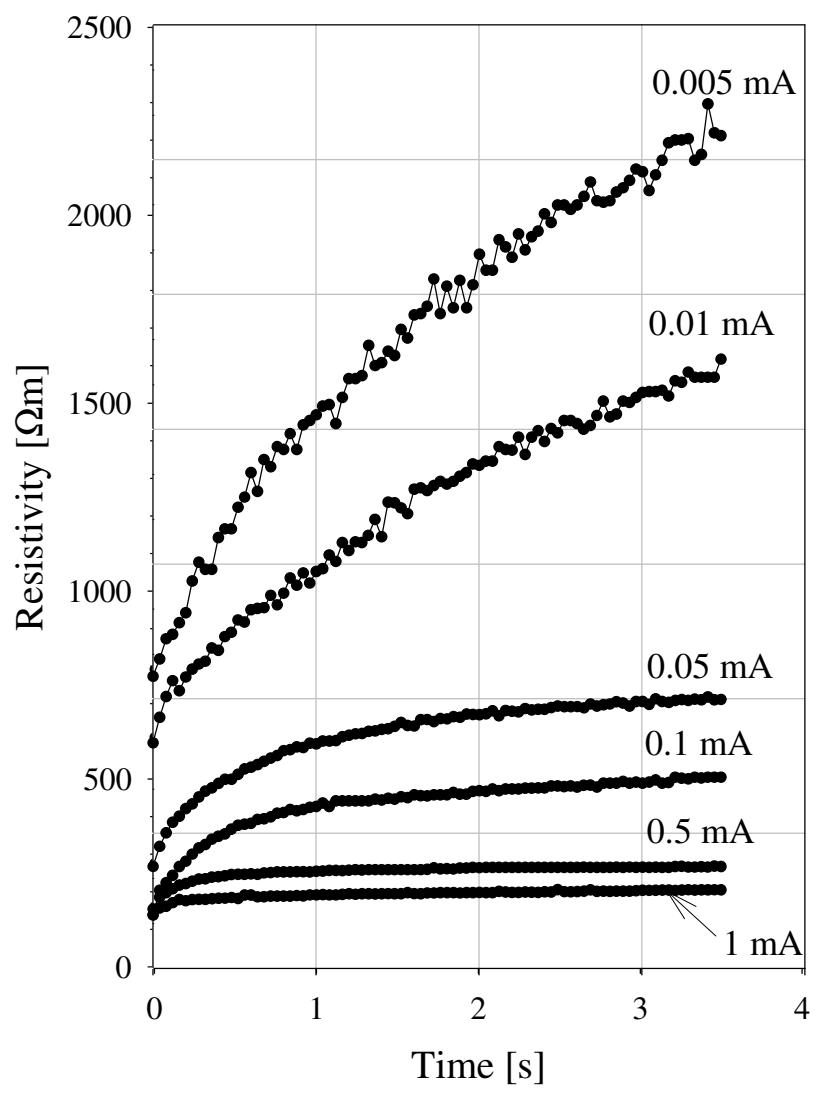

Fig. 2. Calculated resistivity of sandstone sample 226A for different amplitude of applied current.

containing straight half limited capillaries does not depend on structural and physical properties of pores and pores' electrolyte. This model is not common in real structures of interlaced pores in sediments. Also let us note regardless of mentioned unequal transport properties in case of membrane polarization the Eqs. (1) and (2) do not contain the most important parameters of current flow in pores' system - transfer numbers. However this model as well as equivalent electrical circuit models has been widely used to describe electrode polarization parameters and has resulted in two important conclusions being made which have been accepted by all geophysicists, namely: 1 . Processes of IP at time on and time off are the same. 2. There is a linear dependence between applied electrical current and IP amplitude. Practically all existing instruments register transient decay during time-off.

Physical modelling has been performed at the CGS for several years using the instrument RIP built by M. Hauger. However, the results of laboratory measurements very often show the opposite. Figure 1 demonstrates the result of laboratory measurements of sample of sandstone number 226A.

A constant current pulse train is generated in the transmitter and passed through the sample via the current electrodes in the sample holder. The porosity of sample is $16 \%$. The

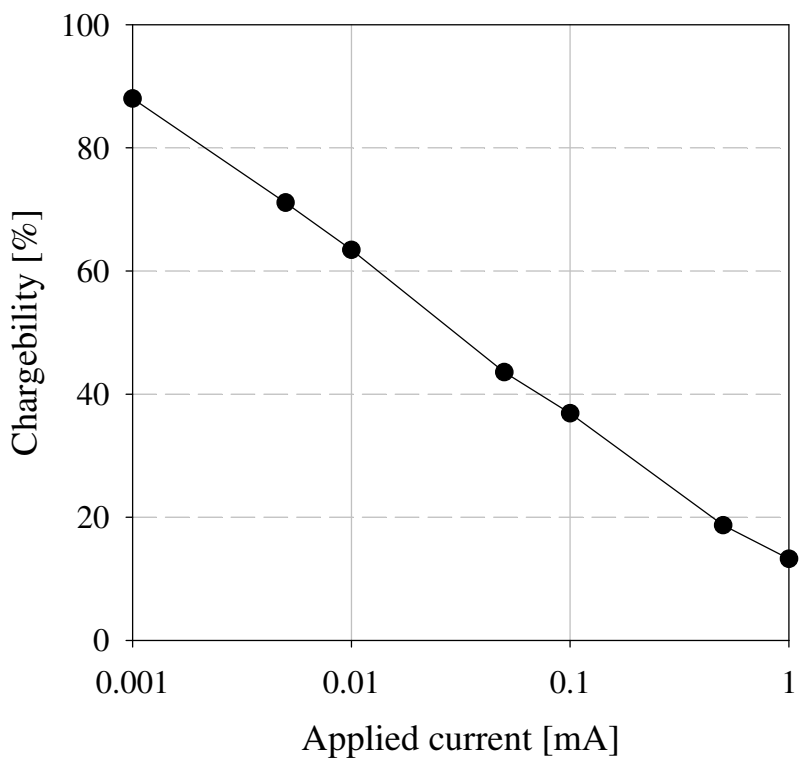

Fig. 3. Measured chargeability vs. applied current. Sample 226A.

measurements were performed for different electrical currents (from $0.05 \mathrm{~mA}$ to $1 \mathrm{~mA}$ ). The voltage is measured at the electrodes connected to the sample. The measured voltage shows no linear dependence on applied current. Since the geometrical shape of the sample is known, resistivity can be calculated as follows:

$\rho=\frac{V}{I} \frac{S}{L}$

where $V$ is the voltage, $I$ is constant current setting, $S$ is the surface area of sample, and $\mathrm{L}$ is the sample length. Figure 2 demonstrates calculated resistivity of sample for different amplitude of applied current. Obviously the measured resistivity of sample depending on current and that phenomenon does not suit the Ohm's law.

Moreover the Fig. 3 demonstrate the value of chargeability measured by different current and calculated as $\eta=V_{0.5} / V_{d}$, where $V_{05}$ is a voltage measured at the time $0.5 \mathrm{~s}$ and $V_{d}$ is a primary voltage. This figure demonstrates that the chargeability also depends on the magnitude of the applied current and increases when current decreases.

Now we came to the questions: What process of IP are we measuring? How far are our measured parameters from real geo-electrical parameters? Schön (1996) has added the following remark: "The surfaces of silicate minerals often carry negative charges. It is therefore not only found in clay minerals. The effect of the interface on physical properties of porous rocks (electrical and hydraulic) is controlled by the ratio of the interface (or double layer) thickness of pore radius. For large pore radii the influence of the double layer is small, and ion motion is nearly undistributed. But for the small pore radius (or section with small radii) the double 


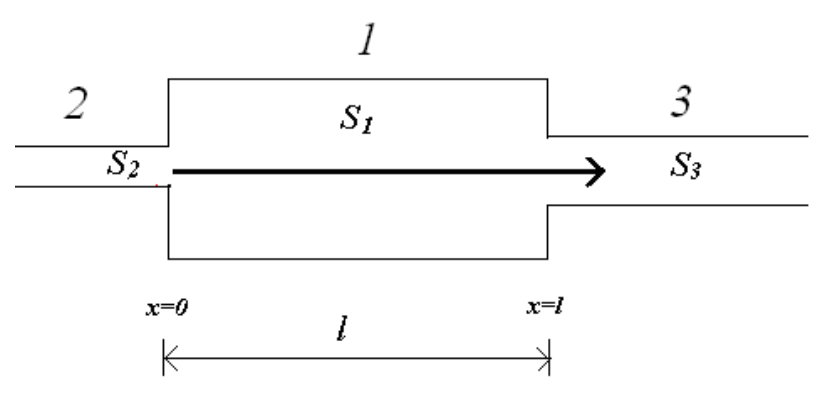

Fig. 4. Model of three connected capillaries.

layers could touch each other and act as a barrier to anions. Under the influence of an electric field a varying concentration of anions and cations result. This behaviour can be described as passive and active sections where the notation "active" and "passive" refers to the polarization origin within the porous rocks." This type of polarization is mentioned in the book by J. Schön as polarization by constrictivity of pores. However this kind of polarization hardly ever develops. We mentioned already Marshal and Madden (1959). These authors as well as Kobranova (1986) showed that this type of polarization occurs in sediments containing pores with different surface areas in which the mobilities of ions and transfer numbers are different. They also showed that when electrical current flows through a channel containing pores with different radii (transfer numbers), an excess/loss of ions accumulates at the boundaries. Marshal and Madden (1959) presented the equation of steady-state conditions conductance (with our symbols) as:

$\sigma_{d c}=\frac{F \mathrm{M}_{i k} u_{0}\left(\frac{1}{n_{2 k}}+\frac{A}{B} \frac{1}{n_{1 k}}\right)}{l_{1}\left[\frac{n_{1 k}}{n_{1 a}}\left(1+\frac{A}{B}\right)+\frac{n_{2 k c}}{n_{2 a}}\left(1+\frac{A}{B}\right)\right]}$

where $A=l_{1} / l_{2} \quad B=D_{1 n} / D_{2 n}, l_{1} l_{2}$ are length of large (1) and narrow (2) capillaries, respectively, $D$ is a diffusion coefficient, $u_{0}$ is net concentration of free solution, $n_{2 k}, n_{1 k} n_{2 a}, n_{1 a}$ are transfer numbers of cations and anions in narrow and large capillaries. Subscripts $k$ and $a$ indicate cations and anions respectively, numerical subscript indicate the number of pores $(1,2)$ respectively. However the authors did not analyze when steady-state condition occurs and physical phenomena and mathematical consideration explaining this condition. We can only refer to Pape and his co-authors (1987). They tried to adjust an electrical circuit as well as fractal model to describe processes causing by constrictivity of pores. Some aspects of this kind of polarization were discussed by Titov et al. (2002).

This paper intends to develop the model of polarization by constrictivity of pores by giving briefly a mathematical consideration of the process and discusses the physical phenomena occurring during time-on and time-off of applied electri-

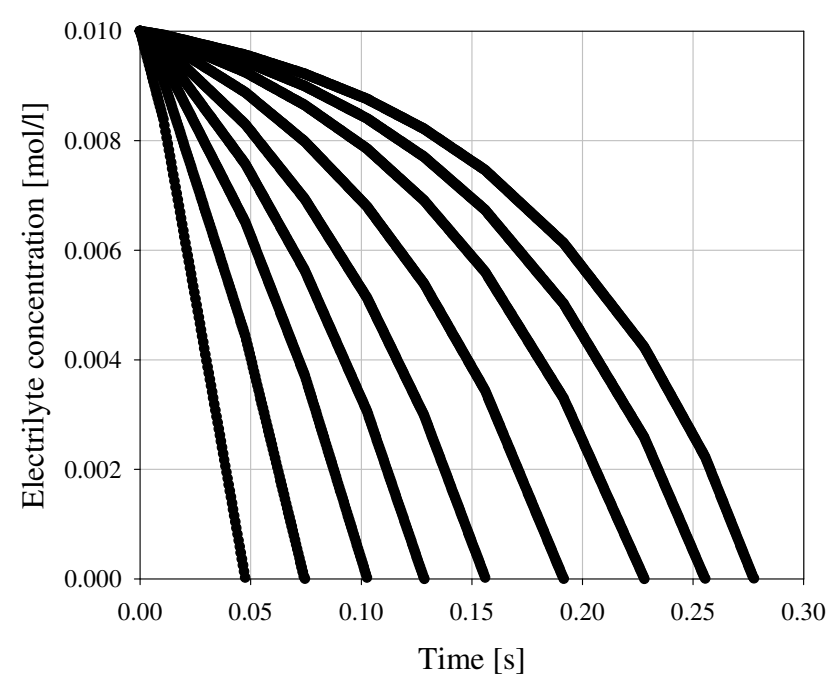

Fig. 5. Boundary conditions in the pores. Sample contains numerous pore configurations.

cal current. Therefore we shall also name this kind of polarization as membrane polarization because the origin of this process is to form membranes between connected pores.

\section{Theoretical consideration}

The complete theoretical consideration of membrane polarization caused by constrictivity of pore radii was developed and published (Zadorozhnaya and Hauger, 2007, 2008a, b). Here we mention only the solutions of the mathematical problems and discuss the most important obtained results.

The duration of the polarization process in pores is controlled by the transfer numbers, radii of the connected pores, and amplitude of the electrical current. If a large pore connects to a narrow pore, the ion concentration in the vicinity of the contact decreases. Our aim is to provide modelling of membrane polarization in rocks with complex structures of pore spaces and prove the issues mentioned above. The primary model (cell) consists of three connected pores with surface areas $S_{1}$ (central pore), $S_{2}$ and $S_{3}$ are respectively left and right pores (Fig. 4). Afterwards more complicated models containing many connected pores of different sizes and transfer numbers are submitted. The solutions are presented for time-on and time-off. Then we also intend to show that the resistivity of sediments change during the application of an electrical current.

Considering the problem of salinity distribution of ions in a solution filling pores, when a spontaneous electrical current is applied (time-on). Diffusion distribution in a bar, with controlled salinity on its ends, can be used as a solution for 
Table 1. Parameters of model.

\begin{tabular}{lllllll}
\hline & $r_{1}[\mathrm{~mm}]$ & $r_{2}[\mathrm{~mm}]$ & $r_{3}[\mathrm{~mm}]$ & $n_{1 k}$ & $n_{2 k}$ & $n_{3 k}$ \\
\hline Model 1 & $4.0 \mathrm{e}-5$ & $1.0 \mathrm{e}-5$ & $1.4 \mathrm{e}-5$ & 0.798 & 0.949 & 0.976 \\
Model 2 & $1.0 \mathrm{e}-5$ & $1.4 \mathrm{e}-5$ & $4.0 \mathrm{e}-5$ & 0.949 & 0.976 & 0.798 \\
Model 3 & $1.4 \mathrm{e}-5$ & $1.0 \mathrm{e}-5$ & $4.0 \mathrm{e}-5$ & 0.976 & 0.949 & 0.798 \\
Model 4 & $1.4 . \mathrm{e}-5$ & $4.0 \mathrm{e}-5$ & $1.0 \mathrm{e}-5$ & 0.976 & 0.798 & 0.949 \\
\hline
\end{tabular}

this case (Koshlyakov et al., 1970). The general diffusion equation is the following:

$$
\frac{\partial u}{\partial t}=a^{2} \frac{\partial^{2} u}{\partial x^{2}}
$$

Where $u$ is the salinity of the solution, $a^{2}=D$ is a diffusion coefficient. The boundary conditions and initial conditions are:

$\left.u\right|_{x=0}=\psi_{1}(t),\left.u\right|_{x=l}=\psi_{2}(t)$ and $\left.u\right|_{t=0}=\varphi_{\mathrm{on}}(x)$,

where $l$ is the length of the central pore $1, \varphi_{\text {on }}(t)$ is constant and equal to the salinity of cations and anions at steady condition. It was shown (Zadorozhnaya and Hauger, 2007) that the boundary conditions can be written as follows:

$\left.u\right|_{t=0}=u_{0 k}+u_{0 a}=\varphi_{\text {on }}(x), \quad u_{0 k}=u_{0 a}=u_{0} / 2$

$$
\left.u\right|_{x=0}=u_{0 k}+u_{\Delta 2 k}(t)+u_{0 a}+u_{\Delta 2 a}(t)=\psi_{1}(t),
$$$$
\left.u\right|_{x=l}=u_{0 k}+u_{\Delta 3 k}(t)+u_{0 a}+u_{\Delta 3 a}(t)=\psi_{2}(t) \text {, }
$$

where

$$
\begin{aligned}
& u_{\Delta 2 k}(t)=\frac{I^{2} \mathrm{M}_{k} t}{F z D S_{1} S_{2} \sigma_{k}}\left(n_{2 k}-n_{1 k}\right), \\
& u_{\Delta 3 k}(t)=\frac{I^{2} \mathrm{M}_{k} t}{F z D S_{1} S_{2} \sigma_{k}}\left(n_{1 k}-n_{3 k}\right) \\
& u_{\Delta 2 a}(t)=\frac{I^{2} \mathrm{M}_{k} t}{F z D S_{1} S_{2} \sigma_{a}}\left(n_{1 a}-n_{2 a}\right), \\
& u_{\Delta 3 a}(t)=\frac{I^{2} \mathrm{M}_{a} t}{F z D S_{1} S_{2} \sigma_{a}}\left(n_{3 a}-n_{1 a}\right) .
\end{aligned}
$$

Here numerical subscript indicate the number of pores (1, 2 and 3$), u_{0}$ is the initial salinity of the solution, $u_{\Delta}$ is the excess of salinity at the boundary between pores, $\sigma$ is the conductivity of ions, $n$ is the transfer number of ions in the pore, $I$ is an electrical current flowing in the pore, $t$ is time. Equation (8) show a linear dependency of salinity on time at the boundaries between capillaries and depends on the square value of the electrical current $I$. Obviously if $n_{2}=n_{1}$ and/or $n_{3}=n_{1}$ there is not an excess of ions on the contacts between pores. On the other hand if pore radii are different but both are large the influence of the double electrical layers (DEL) can be neglected because $n_{2}=n_{1}=0.5$ and/or $n_{3}=n_{1}=0.5$ and no excess of ions occurs at the boundaries.
Table 2. Model of sample consisting 12 cells.

\begin{tabular}{llllll}
\hline Number of cells & $r_{1}$ & $r_{2}$ & $r_{3}$ & $l_{1}$ & $n$ \\
\hline 1 & $1.3 \mathrm{e}-6$ & $1.2 \mathrm{e}-8$ & $1.4 \mathrm{e}-8$ & $9.5 \mathrm{e}-4$ & 50 \\
2 & $1.1 \mathrm{e}-6$ & $2.0 \mathrm{e}-8$ & $2.0 \mathrm{e}-8$ & $8.5 \mathrm{e}-4$ & 20 \\
3 & $1.15 \mathrm{e}-6$ & $1.3 \mathrm{e}-8$ & $1.4 \mathrm{e}-8$ & $6.4 \mathrm{e}-4$ & 50 \\
4 & $6.5 \mathrm{e}-7$ & $1.3 \mathrm{e}-8$ & $1.4 \mathrm{e}-8$ & $6.4 \mathrm{e}-4$ & 75 \\
5 & $5.0 \mathrm{e}-7$ & $1.2 \mathrm{e}-8$ & $2.0 \mathrm{e}-8$ & $5.5 \mathrm{e}-4$ & 100 \\
6 & $4.0 \mathrm{e}-7$ & $1.7 \mathrm{e}-8$ & $1.8 \mathrm{e}-8$ & $4.7 \mathrm{e}-4$ & 175 \\
7 & $3.0 \mathrm{e}-7$ & $1.5 \mathrm{e}-8$ & $1.6 \mathrm{e}-8$ & $4.0 \mathrm{e}-4$ & 200 \\
8 & $2.0 \mathrm{e}-7$ & $1.5 \mathrm{e}-8$ & $1.5 \mathrm{e}-8$ & $3.5 \mathrm{e}-4$ & 250 \\
9 & $1.7 \mathrm{e}-7$ & $1.6 \mathrm{e}-8$ & $1.6 \mathrm{e}-8$ & $4.4 \mathrm{e}-4$ & 200 \\
10 & $1.5 \mathrm{e}-7$ & $1.8 \mathrm{e}-8$ & $1.6 \mathrm{e}-8$ & $3.5 \mathrm{e}-4$ & 200 \\
11 & $1.3 \mathrm{e}-7$ & $0.8 \mathrm{e}-8$ & $1.6 \mathrm{e}-8$ & $1.7 \mathrm{e}-4$ & 200 \\
12 & $1.2 \mathrm{e}-7$ & $1.5 \mathrm{e}-8$ & $1.3 \mathrm{e}-8$ & $1.0 \mathrm{e}-4$ & 250 \\
\hline
\end{tabular}

The solution of (5) can be found as the following series:

$u(x, t)=\sum_{n=1}^{\infty} T_{n}(t) \cdot \sin \frac{n \pi x}{l}$,

If $\varphi_{\text {on }}=$ const than $\psi_{1}(t)-(-1)^{n} \psi_{2}(t)=Y+X \cdot t$, where $X=\left(K_{12}-(-1)^{n} K_{31}\right)$,

$$
\begin{aligned}
& Y=\left(u_{0}(1-(-1))^{n}\right), \\
& K_{12 k}=\frac{I^{2} \mathrm{M}_{k} t}{F z D S_{1} S_{2} \sigma_{k}}\left(n_{2 k}-n_{1 k}\right), \\
& K_{12 a}=\frac{I^{2} \mathrm{M}_{k}}{F z D S_{1} S_{2} \sigma_{a}}\left(n_{1 a}-n_{2 a}\right)
\end{aligned}
$$

$K_{31 k}=\frac{I^{2} \mathrm{M}_{k}}{F_{z} D S_{1} S_{2} \sigma_{k}}\left(n_{1 k}-n_{3 k}\right)$,

$K_{31 a}=\frac{I^{2} \mathrm{M}_{a} t}{F z D S_{1} S_{2} \sigma_{a}}\left(n_{1 a}-n_{2 a}\right)$.

The solution of (5) with boundary conditions (6) can be written as (Zadorozhnaya and Hauger 2007):

$$
\begin{aligned}
& T_{n}(t)=C_{n} \exp (-A t)+\frac{2 n \pi a^{2}}{l^{2}} \\
& {\left[X\left[\frac{t}{A}-\frac{1}{A^{2}}\right]+\exp (-A t)\left(\frac{X}{A^{2}}-\frac{Y}{A}\right)+\frac{Y}{A}\right] .}
\end{aligned}
$$

The calculation shows the excess of salinity localized at pore contacts. It is very important to note that if at one of the contacts ( 2 or 3 ) the salinity of the solution is decreasing, it can reach the situation where the salinity at this contact becomes equal to zero $\left(u_{\Delta 2,3}\left(t_{0}\right)=u_{0}\right)$. In this case it can be expected that disconnection of the electrical circuit will occur (blockage of pore channel). However, the potential difference between the pore ends stays constant. Let us name 
MODEL 1
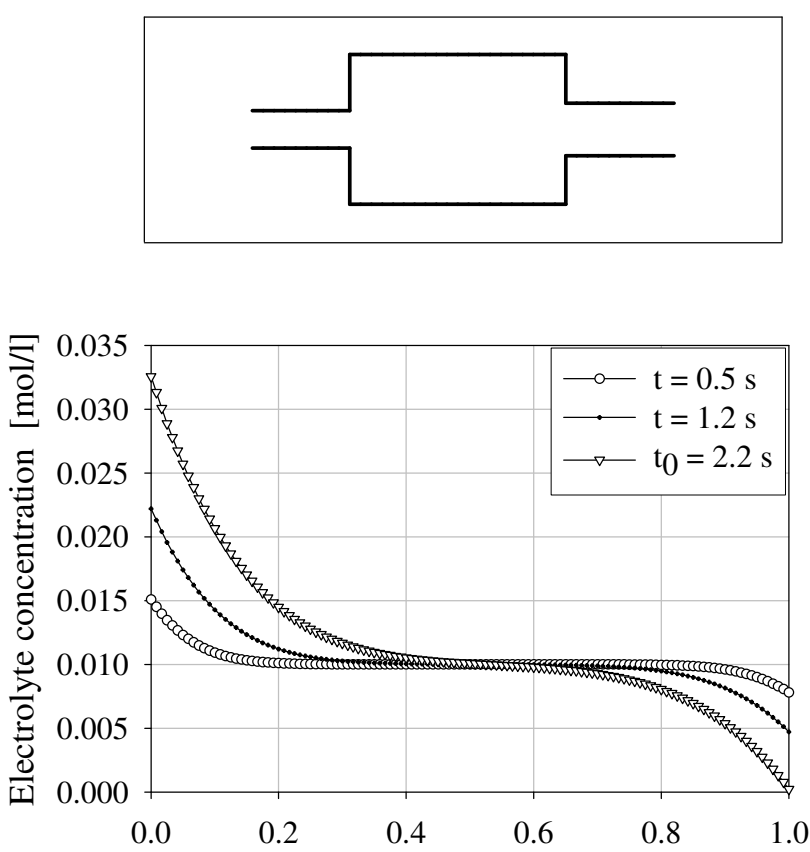

Distance along the pore $[\mathrm{mm}]$

MODEL 3
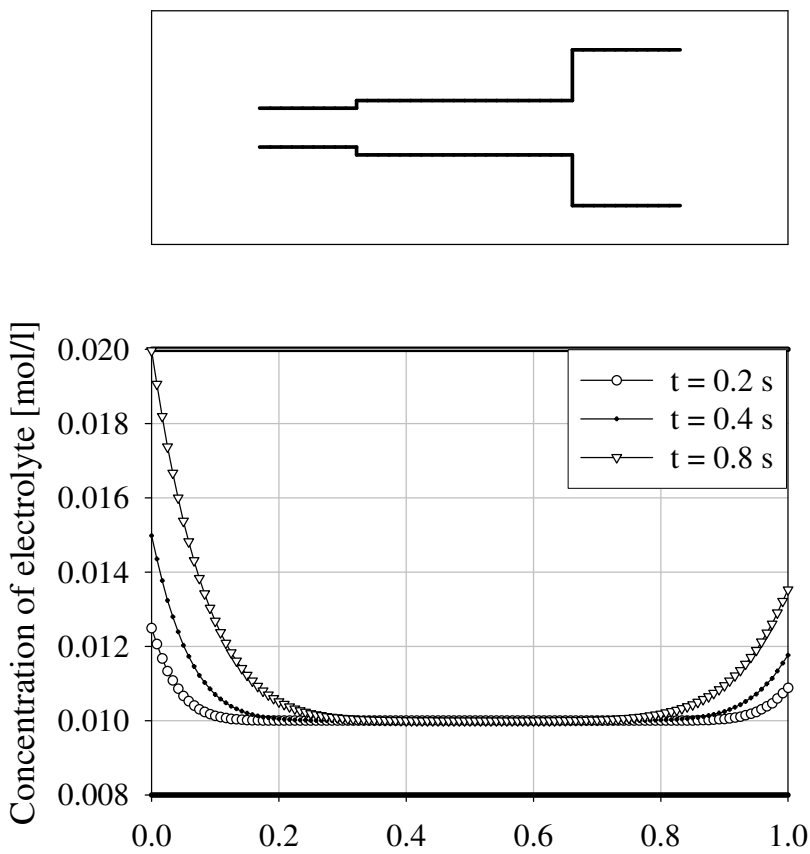

Distance along the pore [mm]

c
MODEL 2
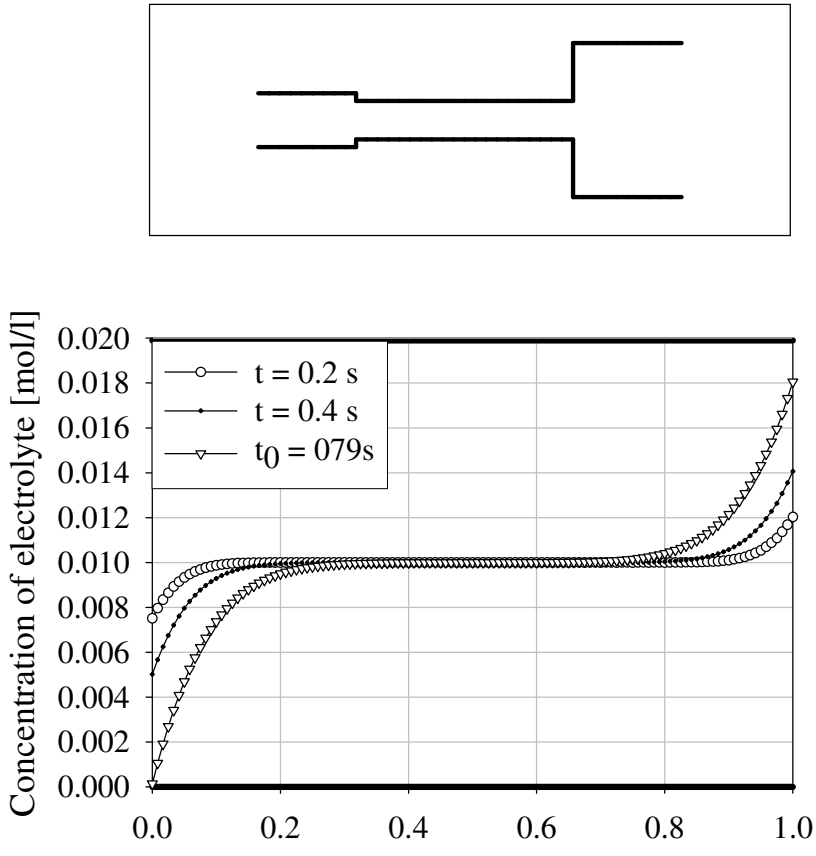

Distance along the pore $[\mathrm{mm}]$

$\mathrm{b}$

MODEL 4
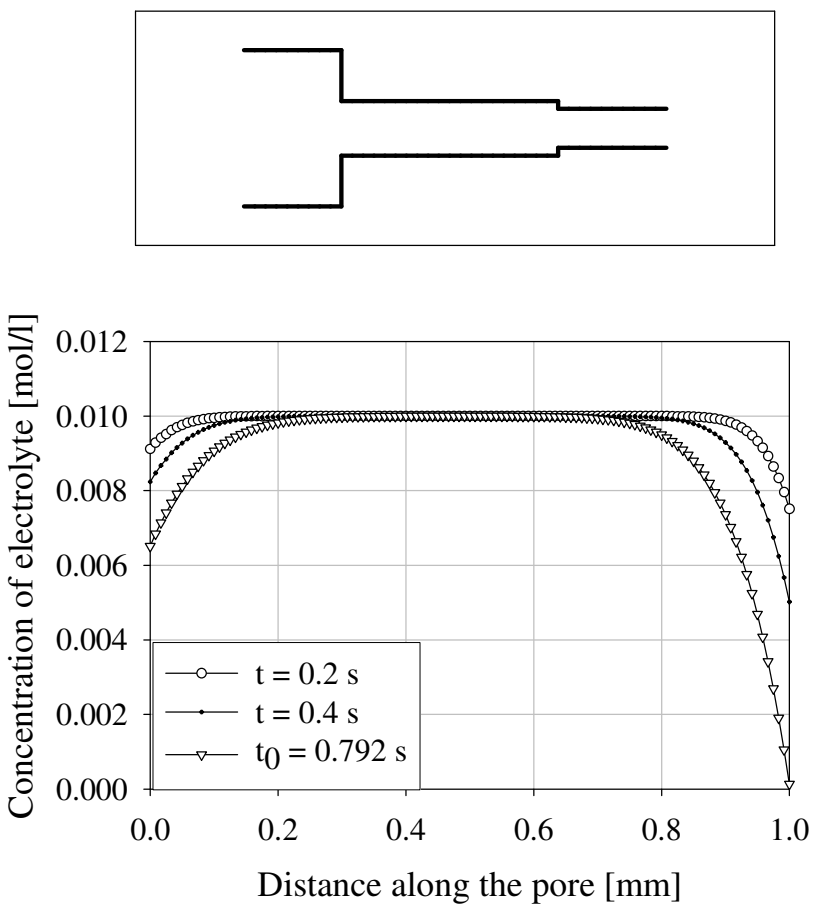

d

Fig. 6. Models of connected pores and concentration distribution at selected times. Model 1 (a), Model 2 (b), Model 3 (c), Model 4 (c). 


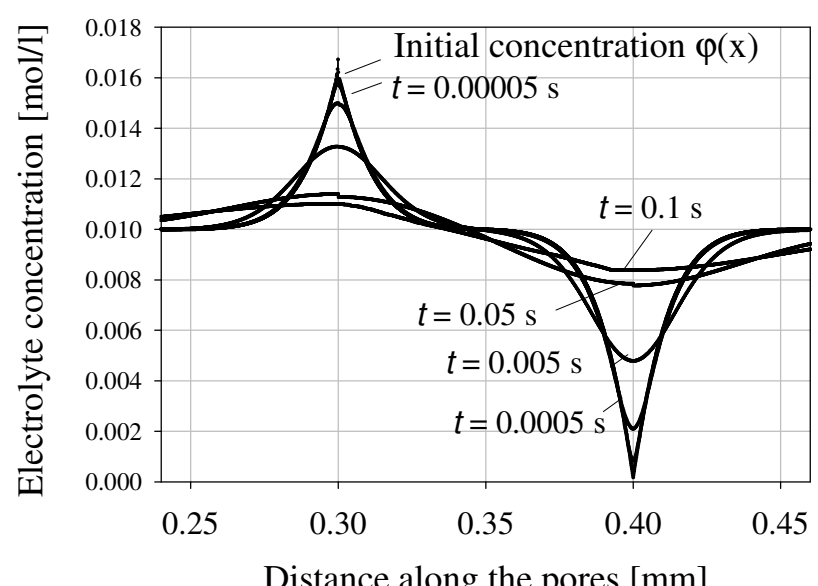

Distance along the pores $[\mathrm{mm}]$

a

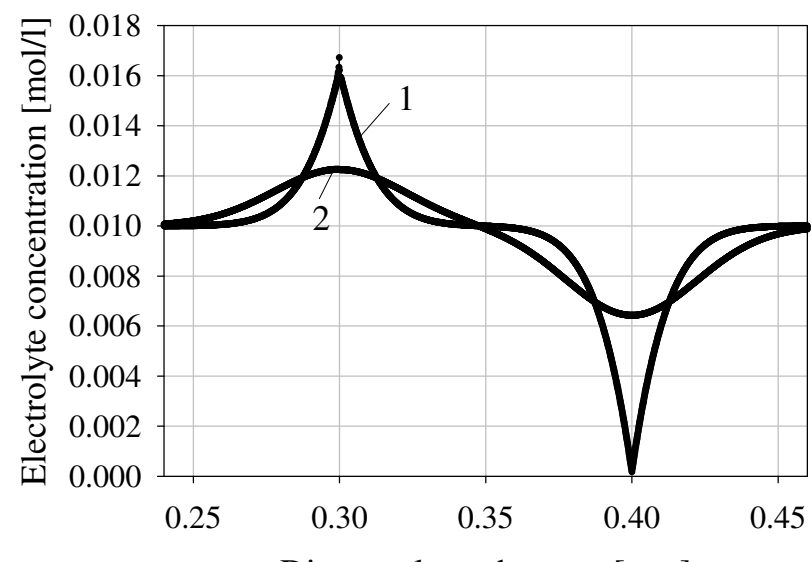

Distnce along the pore $[\mathrm{mm}]$

b

Fig. 7. Model 1. Electrolyte concentration distribution during the time off at selected times. Time of blockage $t_{0}=0.0158$ (a). Comparison of electrolyte concentration distribution at time on (curve 1) and time off (curve 2) at fixed time $0.0158 \mathrm{~s} \mathrm{(b).}$

$t_{0}$ as the critical time of the polarization process. Then $t_{0}$ is equal to:

$t_{0}=-\frac{u_{0 k} F z D S_{1} S_{2} \sigma_{k}}{I^{2} \mathrm{M}_{k}\left(n_{1 k}-n_{3 k}\right)}$.

Now we come to an important conclusion: the duration of the polarization process $t_{0}$ in pores is controlled by the transfer numbers and radii of the connected pores. So the boundary conditions (9) for our problem exist up to time $t_{0}$, after which the electrical circuit ruptures and the potential difference between the pore ends becomes constant.

Figure 5 demonstrates left boundary conditions (between capillaries 1 and 3) for a sample containing ten pore cells. Why are boundary conditions not linear? They remain linear until a pore blockage occurs, then the current finds suitable unblocked pores and continues flowing through these un-blocked pores until another blockage occurs.

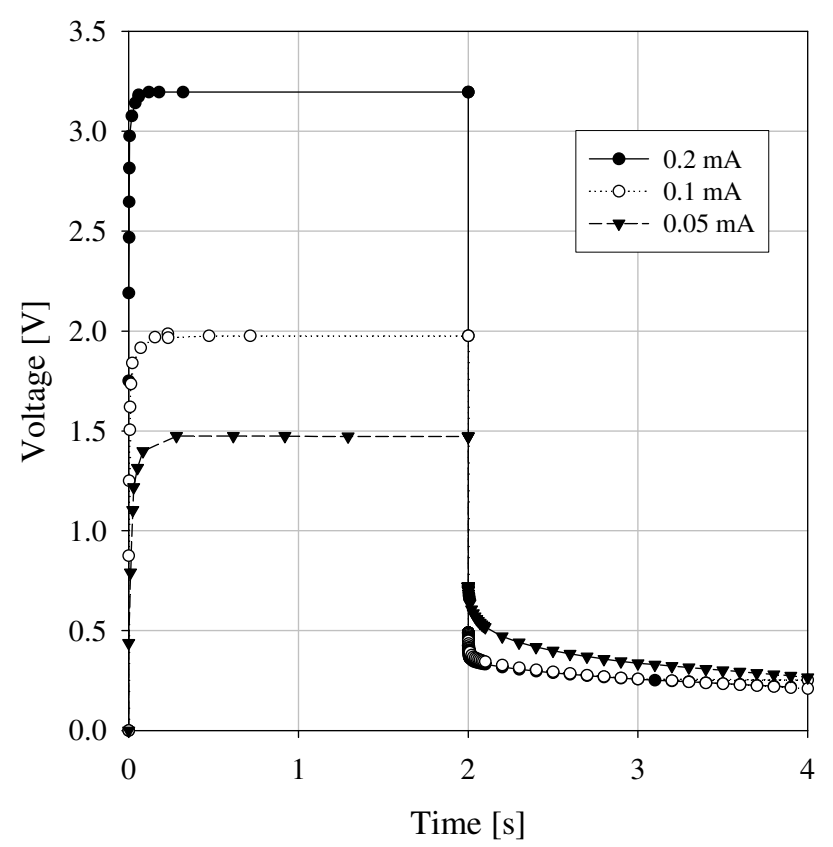

Fig. 8. Mathematical simulation: voltage vs time for different amplitude of electrical current. 12 cell's model.

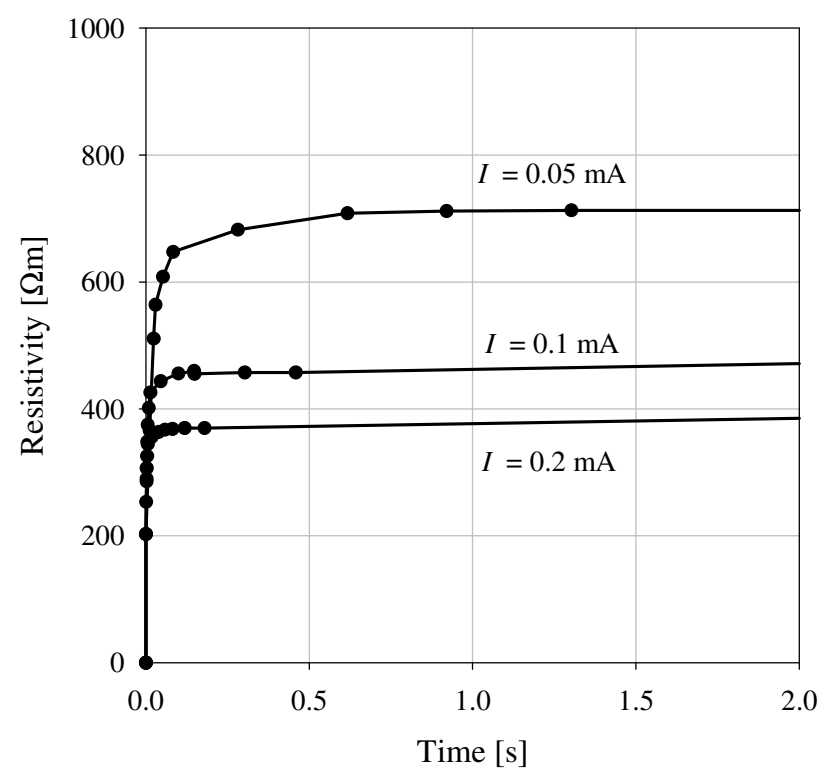

Fig. 9. Mathematical simulation: resistivity vs. time for different amplitude of electrical current. 12 cell's model. 


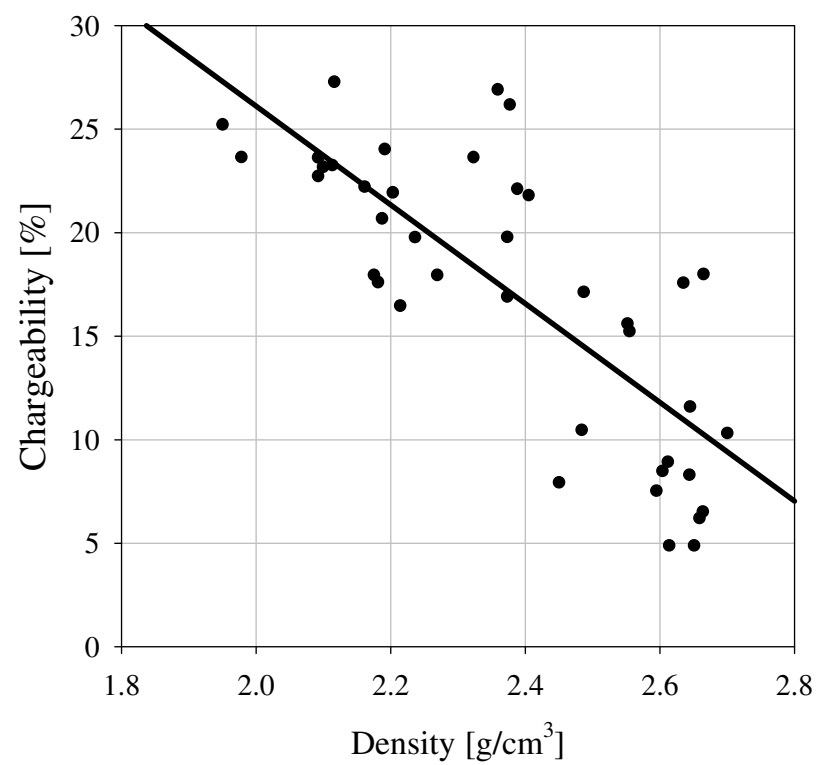

Fig. 10. Cargeability of of samples of kimberlite vs they density.

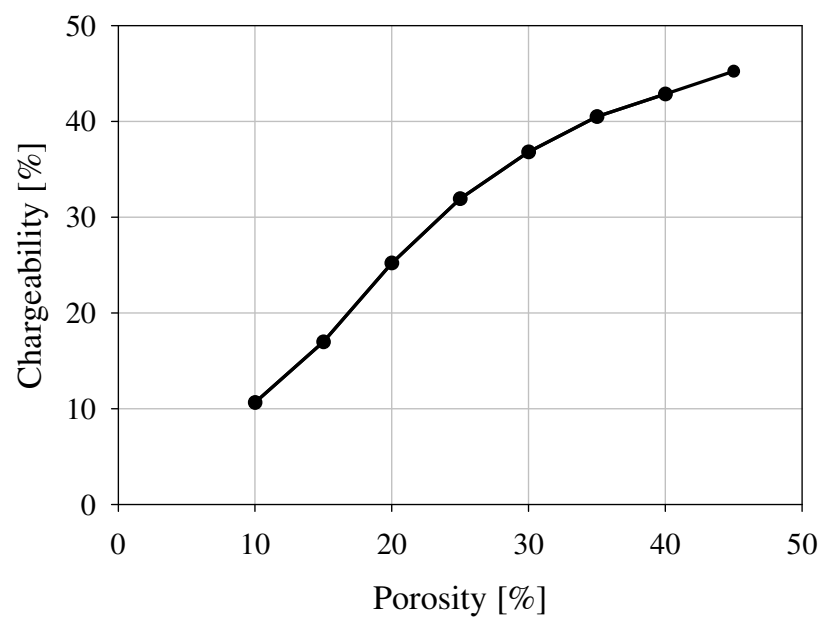

Fig. 11. Mathematical simulation: Chargeability vs porosity of sample.

Calculation of a concentration distribution occurring in the capillaries at time-off is more complicated and is presented as two successful approximations. First approximation:

- Concentration distribution in the pore 1 (Problem of free exchange of ions with host media);

- Numerical boundary conditions following from concentration leveling in pore1;

- Calculation of boundary conditions for surrounding pores (using general equation for unlimited tube);

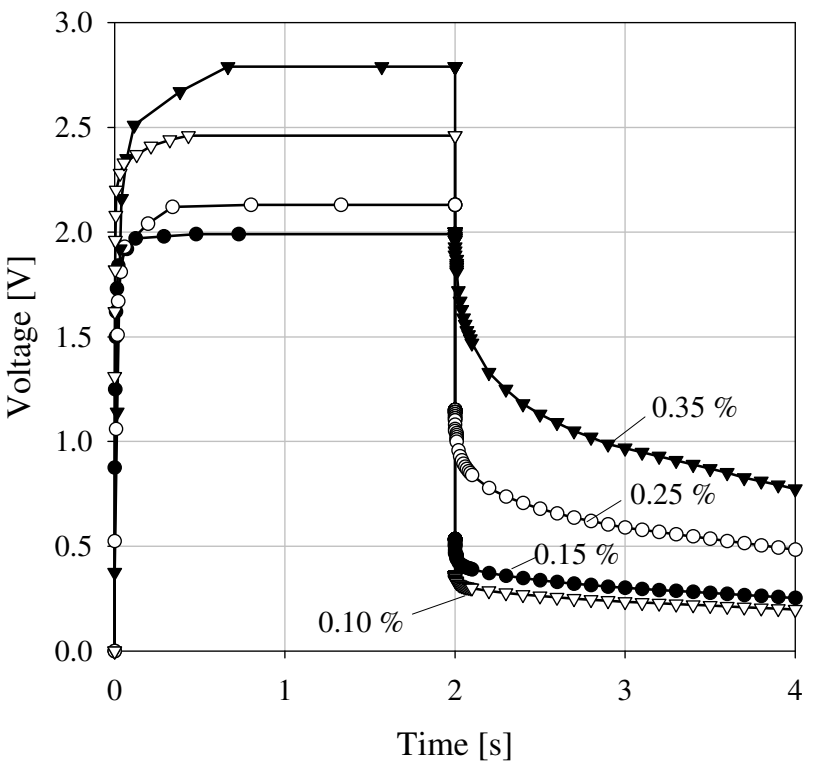

Fig. 12. Mathematical simulation: voltage vs porosity of sample.

- Concentration distribution in connected pores (Diffusion equation for half limited pore with specified boundary and initial conditions).

Second approximation:

- Additional concentration along the pores due to sources of ions at the contacts of pores. (Inhomogeneous diffusion equation where source functions are found as the difference between boundary conditions defined at different sides of connected pores (zero initial conditions).

The calculation showed that after time-off the diffusion process slowly leveled the concentration along the pores reaching the initial concentration.

The boundary and initial conditions of diffusion Eq. (5) are different at time-on and time-off. Consequently the solutions of Eq. (5) for the time-on and time-off are different. Obviously potential and potential differences occurring between two electrodes are also different for both time-on and time-off.

If current is flowing through the sample containing numerous pore configurations the potential can be presented as a sum of potentials that occur due to flowing conductive current $U_{\text {curr }}(t)$ and excess concentration $U_{\text {excess }}(t)$ at the contacts:

$U_{\text {switch on }}(t)=U_{\text {curr }}(t)+U_{\text {excess }}(t)$

If electrical current does not flow through the sample the potential is defined by excess of concentration $U_{\text {excess }}(t)$ only. Then:

$U_{\text {switch off }}(t)=U_{\text {excess }}(t)$. 


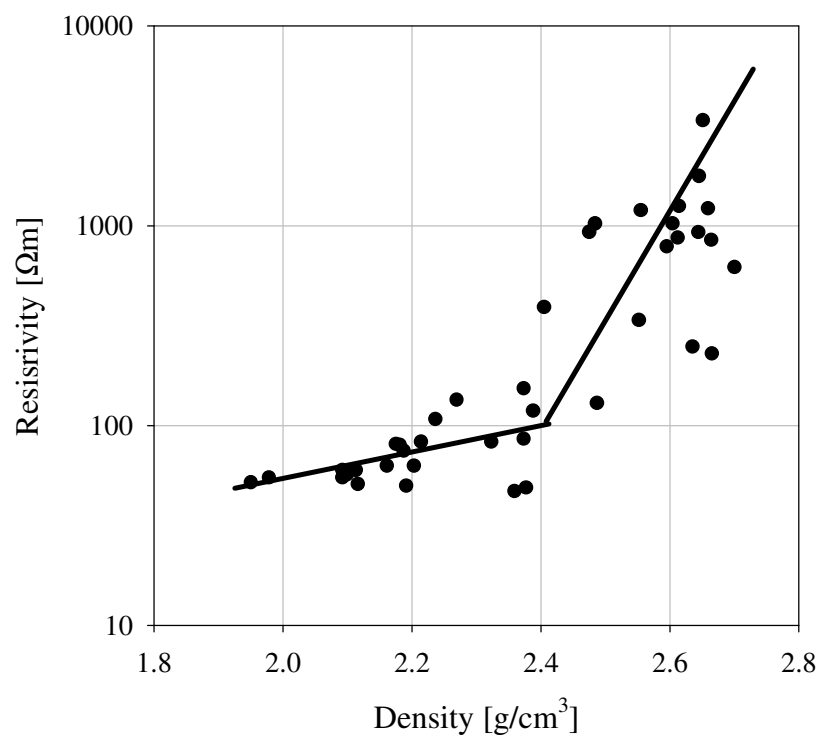

Fig. 13. Resistivity of samples of kimberlyte vs density.

\section{Analyze and discussion}

3.1 Mathematical simulation of salinity distribution along the pores

The computing programs have been written in Mat lab and results of calculations have to be discussed now. For calculations four types of models (Fig. 6a, b, c, d) were used. Parameters of models are shown in the Table 1. Length of main pore is always equal to $1 \mathrm{~mm}$; electrolyte concentration is $0.01 \mathrm{~mol} / \mathrm{l}$. The direction of current flow as shown in the Fig. 4.

Figure $6 \mathrm{a}, \mathrm{b}, \mathrm{c}, \mathrm{d}$ demonstrate salinity distribution in different types of model for the time-on. If a large capillary is connected to a narrow capillary the difference of transfer numbers is negative and a decrease of ion concentration occurs (Fig. 6a, b, c). The duration of the polarization process depends on the pore radii and transfer numbers. Time of blockage is much earlier in model 2 and model 4 (Fig. 6b, d) $(0.79 \mathrm{c}$ ) but $2.2 \mathrm{c}$ in model 1 (Fig. 6a). Model 3 (Fig. 6c) will never be blocked since the concentration of ions in model 4 decrease at both ends of the main pore.

\subsection{Difference at time-on and time-off}

Figure 7a demonstrates the electrolyte concentration distribution during the time off at selected times in model 1. Time of blockage in this model is equal to $t_{0}=0.0158 \mathrm{c}$. The diffusion process slowly leveled the concentration along the pores reaching the initial concentration $0.01 \mathrm{~mol} / \mathrm{l}$.

Figure $7 \mathrm{~b}$ demonstrates the comparison of electrolyte concentration distribution at the same fixed time for time-on and time-off for model 1. As mentioned above if electrical cur-

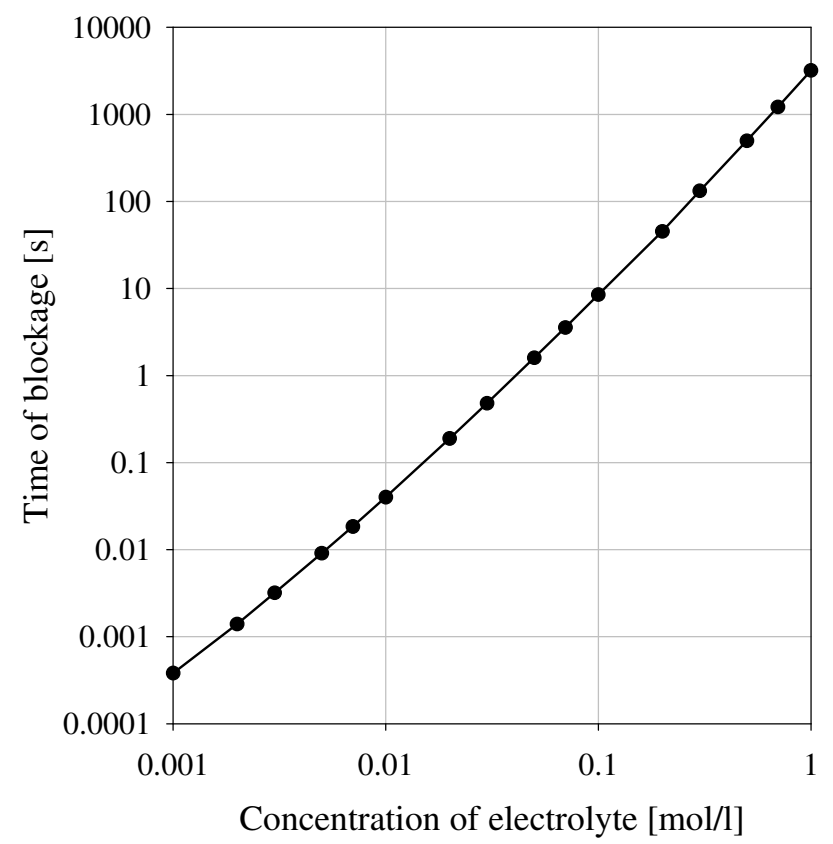

Fig. 14. Time of blockage vs electrolyte concentration. Pore radii: $r_{1}=9.75 \mathrm{e}-8 \mathrm{~m}, r_{3}=6.25 \mathrm{e}-8 \mathrm{~m}$.

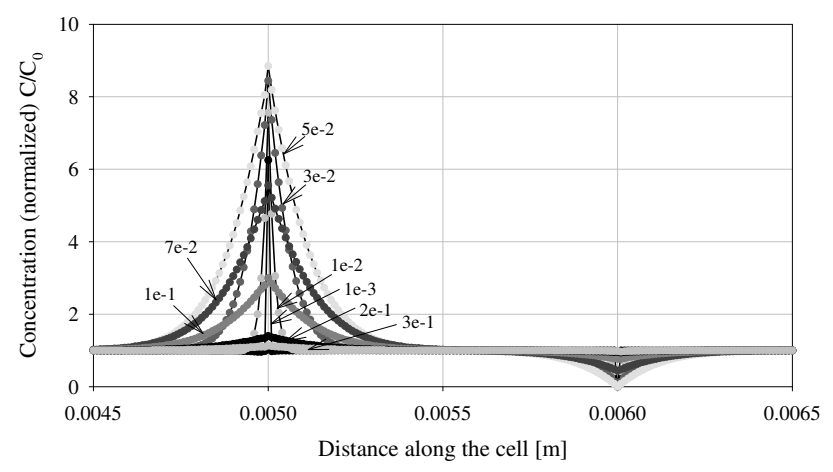

Fig. 15. Concentration distribution along the cell at selected time (1 s or less) for different electrolyte concentration.

rent will be applied to this model then blockage of pores' channel occurs at the time $0.0158 \mathrm{~s}$ a. However at the same time after time-on of electrical current the ions are neither leveled completely nor even leveled considerably (Fig. 7b). Obviously the process of diffusion is much slower than concentration distribution due to applied current (time-on). This fact has been proved by a large number of measurements done by Hauger in CGS (see Fig. 12 as example).

\subsection{Voltage and electrical current}

Non-linear voltage on applied current has been proved through laboratory measurements (Fig. 1). This phenomenon 

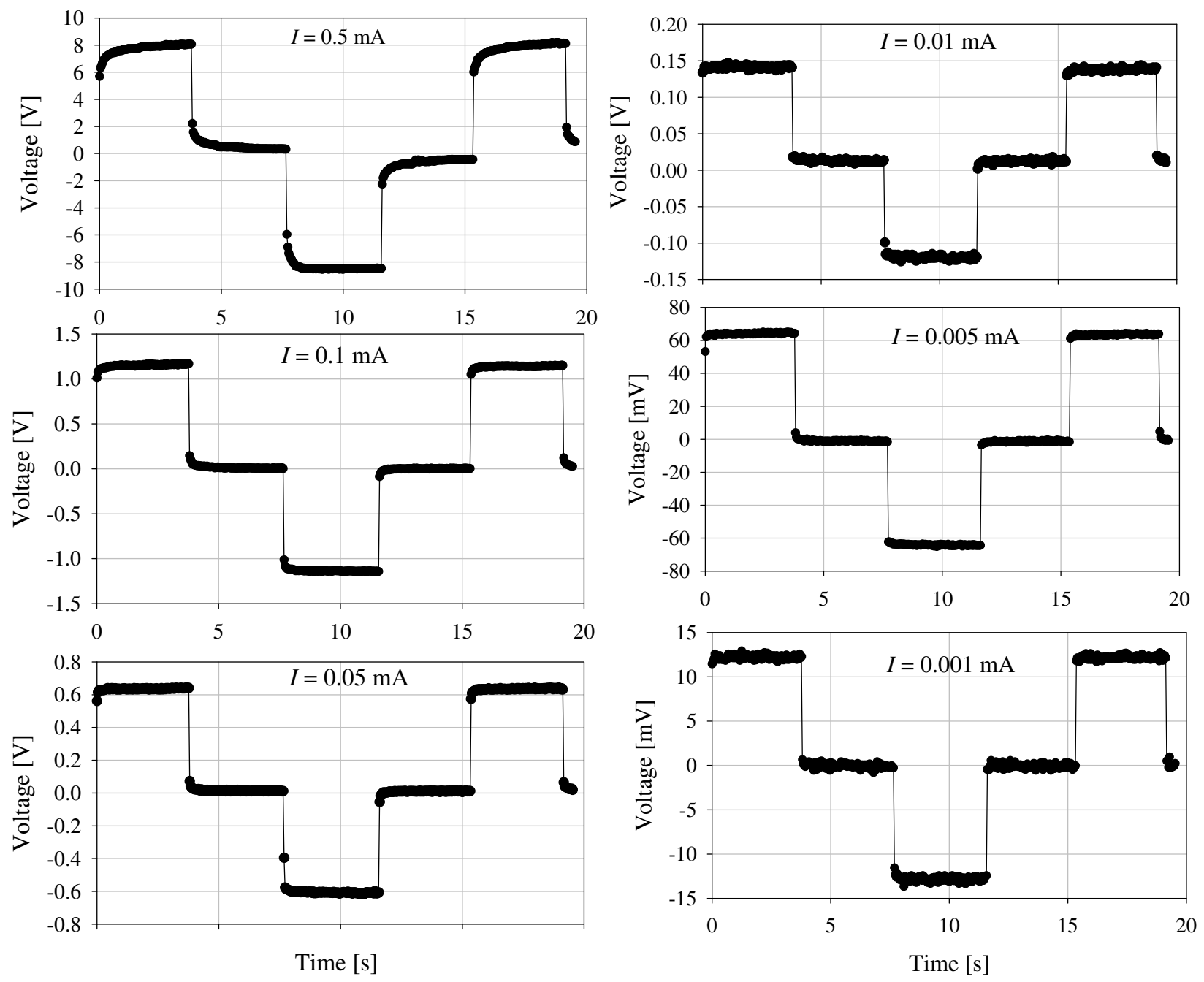

Fig. 16. Laboratory measurements of sandstone $261 \mathrm{C}$ filled by salty water.

follows from boundary conditions (9), which are having current, squared $\left(I^{2}\right)$. Let us analyze mathematical simulation of IP effect depending on current. Usually rocks contain numerous numbers of pore configurations and blockage of pores occurs all the time for the duration of current flow. Let us select petrophysical model consisting of 12 types of cells (Table 2). The ratio of cells with different surface areas (source of IP effect) and straight capillaries where IP effect does not occur is 0.117 , it means $11.7 \%$ of capillaries have surface areas and transfer numbers different for connected pores. Mathematical simulations (Fig. 8) confirmed results obtained by laboratory measurements namely voltage increases vs. increasing current. However there is no linear dependence between both parameters. Why does this occur? If current is big enough then blockage of pores occurs at the earlier times. In this case ions blocked capillaries are located very close to the contacts and the amount of ions involved into this process is very small. So the contribution of $U_{\text {excess }}$ is very small and voltage is defined by conductivity current $U_{\text {curr. }}$. When time of blockage occurs later the amount of ions involved with the polarization process increases (see Fig. 7a) and the ratio between $U_{\text {curr }}$ and $U_{\text {excess }}$ increases as well. In this case the resistivity of sample also increases (Fig. 9).

It is very important that the values of $U_{\text {excess }}$ depend on pore radius. It means the maximum contribution to potential and potential difference occurs with larger pores. However as we mentioned above if large pores are dominant in the sample then IP effect will be negligibly small: the transfer numbers of large pores are close to 0.5 and accordingly the transfer numbers difference will be close to zero, and excess of electrolyte concentrations at the vicinity of pore boundaries will also be close to zero (see Eq. 9). If sediments contain narrow pores the contribution of $U_{\text {excess }}$ will be small. The voltage will only be determined by the $U_{\text {curr }}$. So the combination of large and narrow pores controls the value of the membrane IP effect. 


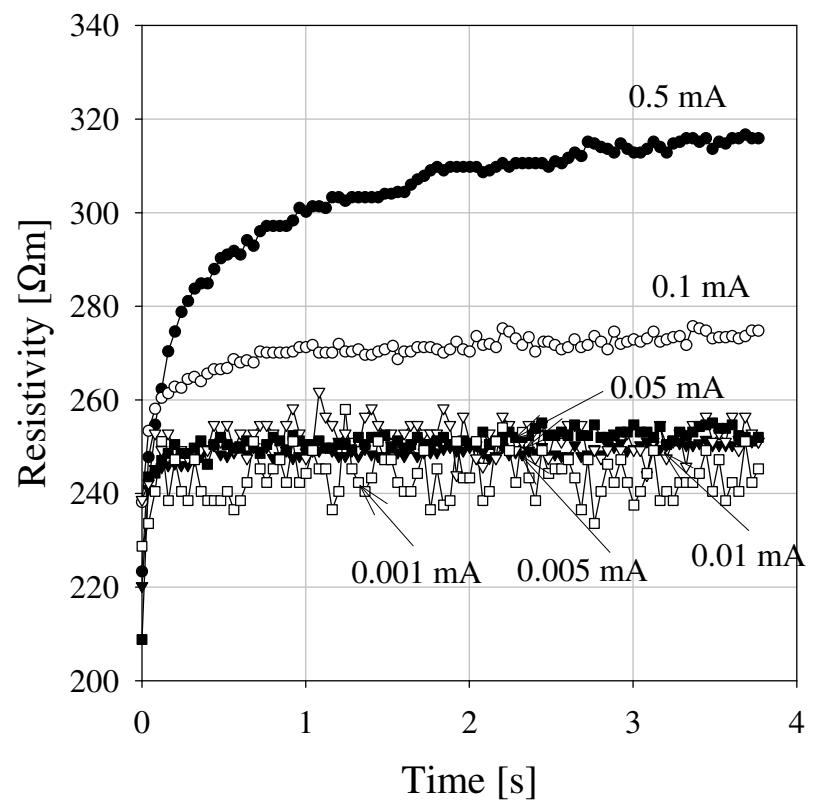

Fig. 17. Calculated resistivity of sandstone sample 261C filled by salty water for different amplitude of applied current.

\subsection{Porosity}

It is well known that resistivity decreases with porosity. The laboratory measurements of samples of kimberlite collected from different depths have been used. Unfortunately parameters of porosity had not been measured during the experiments but only density. However usually rocks with low density are characterized by higher porosity. All measurements were measured with the same amplitude of current $(0.5 \mathrm{~mA})$. The Fig. 10 demonstrates measured chargeability of kimberlites of different density. Obviously chargeability decreases vs. density; it means we can suppose the chargeability is increasing with porosity.

Figure 11 shows calculated chargeability of models (Table 2) with different porosity. The same dependence has been observed: increasing porosity follows increasing chargeability. The explanation of physical phenomenon is the same. High porous rocks involve more ions to induced polarization process than low porous rocks. Process of leveling is slow and as denser clouds of ions concentrate at the contact the longer is the following process of leveling.

Figure 12 shows mathematical modeling of voltage of samples with different porosity. However this dependence is more complicated. In low porous rocks the voltage (resistivity) decreases with decreasing porosity. However as porosity increases so does the amount of ions involved in IP effect and the dependence becomes reversed: increasing porosity results in increasing voltage (resistivity). In this case $U_{\text {excess }}$ is to be dominated by $U_{\text {curr }}$.

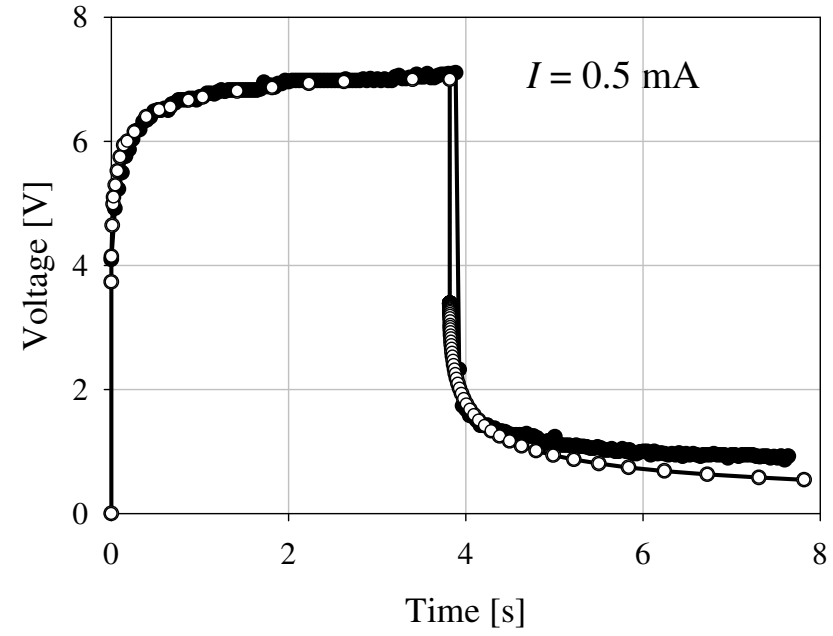

a

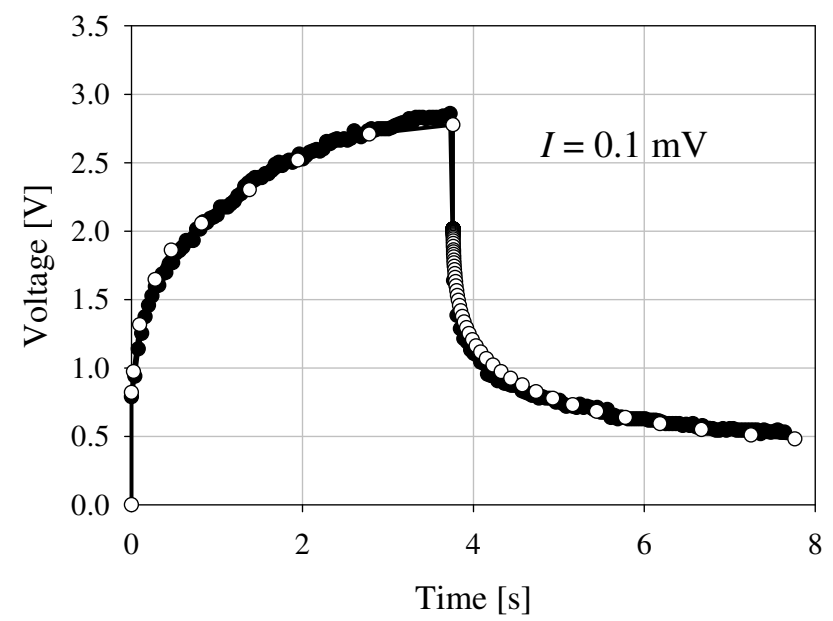

b

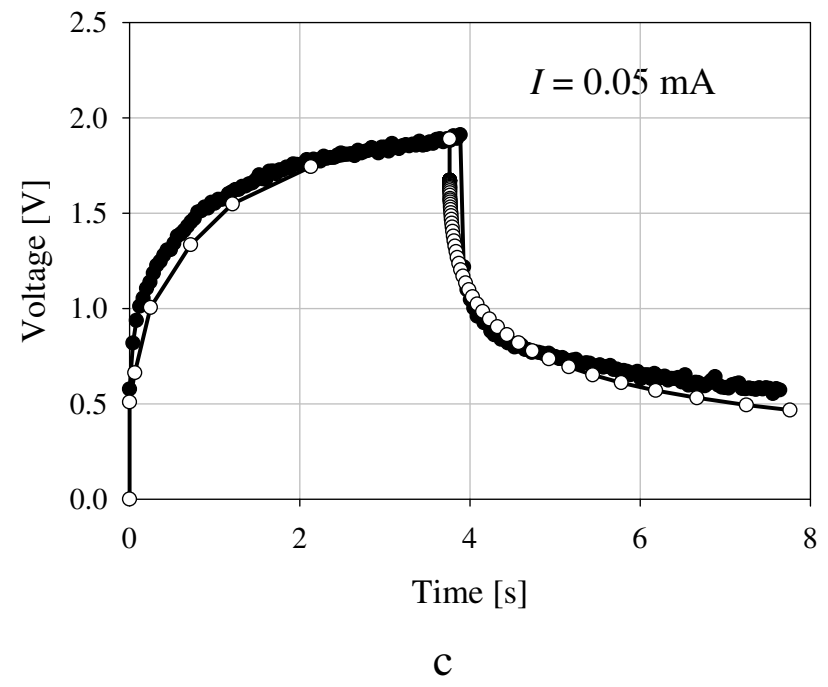

Fig. 18. Mathematical model of membrane polarization of sample 226A (bold dots) and experimental data (circles). 
Table 3. Model of sample 226A containing 22 cells.

\begin{tabular}{lccccl}
\hline $\begin{array}{l}\text { Number } \\
\text { of cells }\end{array}$ & $\begin{array}{c}\text { Radius of } \\
\text { left pore } r_{2}\end{array}$ & $\begin{array}{c}\text { Radius of } \\
\text { main pore } r_{1}\end{array}$ & $\begin{array}{c}\text { Radius of } \\
\text { right pore } r_{3}\end{array}$ & $\begin{array}{c}\text { Length of } \\
\text { main pore } l_{1}\end{array}$ & $\begin{array}{l}\text { Number of } \\
\text { cells in the } \\
\text { sample }\end{array}$ \\
\hline 1 & $1.3 \mathrm{e}-5$ & $2.5 \mathrm{e}-2$ & $1.3 \mathrm{e}-5$ & $1.67 \mathrm{e}-2$ & 3870 \\
2 & $1.4 \mathrm{e}-5$ & $1.18 \mathrm{e}-2$ & $1.4 \mathrm{e}-5$ & $2.00 \mathrm{e}-2$ & 14180 \\
3 & $1.4 \mathrm{e}-5$ & $6.67 \mathrm{e}-3$ & $1.4 \mathrm{e}-5$ & $2.00 \mathrm{e}-2$ & 64440 \\
4 & $1.4 \mathrm{e}-5$ & $4.74 \mathrm{e}-3$ & $1.4 \mathrm{e}-5$ & $2.17 \mathrm{e}-2$ & 97950 \\
5 & $1.4 \mathrm{e}-5$ & $3.85 \mathrm{e}-3$ & $1.4 \mathrm{e}-5$ & $2.00 \mathrm{e}-2$ & 28300 \\
6 & $1.4 \mathrm{e}-5$ & $2.95 \mathrm{e}-3$ & $1.4 \mathrm{e}-5$ & $2.00 \mathrm{e}-2$ & 28300 \\
7 & $1.3 \mathrm{e}-5$ & $2.88 \mathrm{e}-3$ & $1.4 \mathrm{e}-5$ & $1.72 \mathrm{e}-2$ & 270700 \\
8 & $1.3 \mathrm{e}-5$ & $2.82 \mathrm{e}-3$ & $1.4 \mathrm{e}-5$ & $1.47 \mathrm{e}-2$ & 322200 \\
9 & $1.3 \mathrm{e}-5$ & $2.69 \mathrm{e}-3$ & $1.4 \mathrm{e}-5$ & $1.33 \mathrm{e}-2$ & 309300 \\
10 & $1.3 \mathrm{e}-5$ & $2.24 \mathrm{e}-3$ & $1.4 \mathrm{e}-5$ & $1.33 \mathrm{e}-2$ & 451100 \\
11 & $1.3 \mathrm{e}-5$ & $1.92 \mathrm{e}-3$ & $1.4 \mathrm{e}-5$ & $1.27 \mathrm{e}-2$ & 773300 \\
12 & $1.3 \mathrm{e}-5$ & $1.73 \mathrm{e}-3$ & $1.4 \mathrm{e}-5$ & $1.20 \mathrm{e}-2$ & 902200 \\
13 & $1.3 \mathrm{e}-5$ & $1.47 \mathrm{e}-3$ & $1.3 \mathrm{e}-5$ & $1.17 \mathrm{e}-2$ & 1288800 \\
14 & $1.4 \mathrm{e}-5$ & $1.40 \mathrm{e}-3$ & $1.4 \mathrm{e}-5$ & $1.17 \mathrm{e}-2$ & 1353300 \\
15 & $1.4 \mathrm{e}-5$ & $1.28 \mathrm{e}-3$ & $1.4 \mathrm{e}-5$ & $1.17 \mathrm{e}-2$ & 1288800 \\
16 & $1.3 \mathrm{e}-5$ & $1.09 \mathrm{e}-3$ & $1.4 \mathrm{e}-5$ & $1.17 \mathrm{e}-2$ & 1417700 \\
17 & $1.3 \mathrm{e}-5$ & $9.0 \mathrm{e}-4$ & $1.4 \mathrm{e}-5$ & $1.17 \mathrm{e}-2$ & 1675400 \\
18 & $1.3 \mathrm{e}-5$ & $8.7 \mathrm{e}-4$ & $1.4 \mathrm{e}-5$ & $1.17 \mathrm{e}-2$ & 1933200 \\
19 & $1.4 \mathrm{e}-5$ & $7.9 \mathrm{e}-4$ & $1.4 \mathrm{e}-5$ & $1.17 \mathrm{e}-2$ & 2577600 \\
20 & $1.4 \mathrm{e}-5$ & $7.1 \mathrm{e}-4$ & $1.4 \mathrm{e}-5$ & $1.17 \mathrm{e}-2$ & 2964300 \\
21 & $1.4 \mathrm{e}-5$ & $6.4 \mathrm{e}-4$ & $1.4 \mathrm{e}-5$ & $1.17 \mathrm{e}-2$ & 3479800 \\
22 & $1.4 \mathrm{e}-5$ & $5.8 \mathrm{e}-4$ & $1.4 \mathrm{e}-5$ & $1.17 \mathrm{e}-2$ & 3866400 \\
\hline
\end{tabular}

The following dependence presented in semi-logarithm scale can be seen in the Fig. 13. The resistivity of kimberlites decreases very fast from 4000 to $100 \mathrm{Ohmm}$ with decreasing density (i.e. increasing porosity) from 2.8 to $2.6 \mathrm{~g} / \mathrm{cm}^{3}$. However resistivity of low dense (higher porous) rocks remains more or less stable (approximately $80-100 \mathrm{Ohmm}$ ) with further decreasing density from 2.0 to $1.95 \mathrm{~g} / \mathrm{cm}^{3}$. So this example (laboratory measurements and mathematical modeling of resistivity of porous rocks) demonstrates a very complicated relationship between resistivity and porosity of rocks.

\subsection{Electrolyte concentration}

It is known that all kinds of polarization effects exist only if concentration of electrolyte filled pores space of rocks is low. Let us see a mechanism of membrane polarization effect depending on this parameter. The Eq. (12) shows that the time taken to block the pores is linearly dependent on the conductivity of electrolyte $\sigma$. The Fig. 14 demonstrates dependence $t_{0}$ on concentration of electrolyte in a single pores cell with following parameters $r_{1}=9.75 \mathrm{e}-8 \mathrm{~m}$ and $r_{3}=6.75 \mathrm{e}-$ $8 \mathrm{~m}, I=13 \mathrm{e}-13 \mathrm{~A}$. The time of pore blockage is linearly dependant on electrolyte concentration $u$, and transfer number difference decreases. So if $u=0.001 \mathrm{~mol} / \mathrm{l}(0.056 \mathrm{~g} / \mathrm{l}$ for $\mathrm{NaCl}$ solution, fresh, drinking water) when time of blockage oc- curs at the time $3.82 \mathrm{e}-4 \mathrm{~s}$. If $u=0.1 \mathrm{~mol} / \mathrm{l}(5.6 \mathrm{~g} / \mathrm{l}$, salty water), when time of blockage occurs at the time $8.5 \mathrm{~s}$. If $u=1 \mathrm{~mol} / \mathrm{l}$ ( $56 \mathrm{~g} / \mathrm{l}$, concentrated solution), when time of blockage occurs at the time $3204 \mathrm{~s}$. It means the process of concentration of ions in the vicinity of contracted pores with different surface areas becomes slower with increasing concentration of electrolyte.

The Fig. 15 shows the salinity distribution along the pore at time $1 \mathrm{~s}$ (or early if blocked pores occurs at the earlier than $1 \mathrm{~s} \mathrm{time)}$ for our model (Table 2). It is clear that if concentration is low then blockage of pores occurs at the earliest time. However in this case there could be no considerable excess of ions at the contact. This effect is similar to the effect of salinity distribution of ions due to high amplitude current: the electrical resistivity is determined by non-blocked capillaries and the influence of excess of ions $u_{\Delta a, K}$ is minimal. Increasing the salinity of water provides an excess of ions at the contacts. However the velocity of ion accumulation becomes slow. If the concentration of solution is very high (as example $1 \mathrm{~mol} / \mathrm{l}$, it means $56 \mathrm{~g} / \mathrm{l} \mathrm{NaCl}$ ), then the process of ions accumulation would not have even started at the time $1 \mathrm{~s}$. So it takes a lot of time to observe a non- neglectible IP effect in samples filled by salt water. 


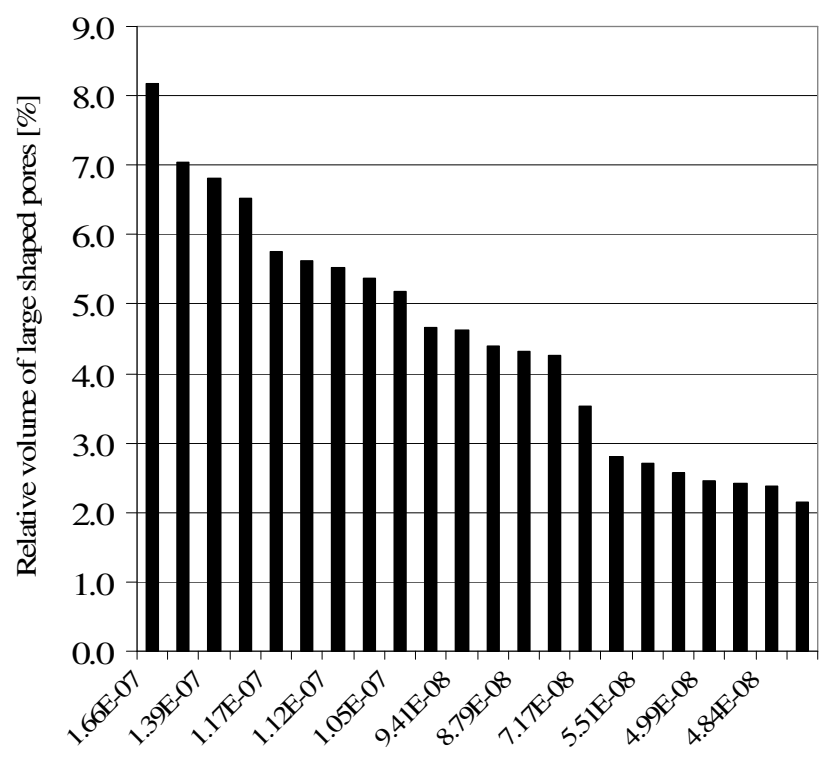

Volume of pore $\left[\mathrm{mm}^{3}\right]$
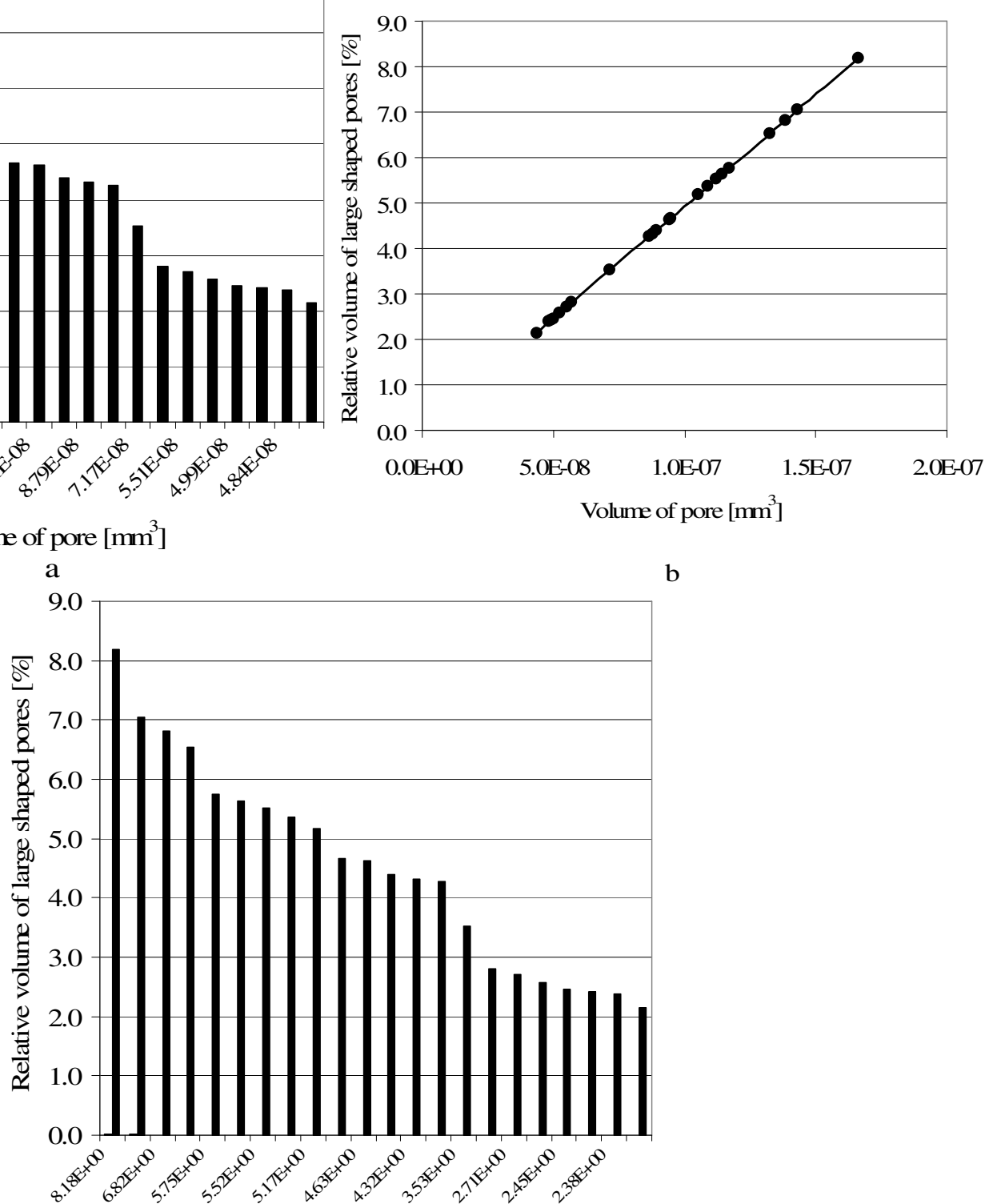

Pore radius $[\mathrm{mm}]$

c

Fig. 19. Pore size distribution of sample 226A. (a) Histogram showing relative volume of cylindrical shaped pores vs. their volume. (b) Relative volume of cylindrical shaped pores vs. their volume; (c) Histogram showing relative volume of cylindrical shaped pores vs. their pore radius $r_{1}$.

The Fig. 16 demonstrates the measured voltage of a sample of sandstone number $261 \mathrm{C}$, filled by salty water (concentration $7 \mathrm{~g} / \mathrm{l}$ or $0.125 \mathrm{~mol} / \mathrm{l})$. If applied current is high enough the IP effect can be recognized due to earlier blockage of pores. Decreasing current follows linear dependence voltage on current - no IP effect can be observed.
The Fig. 17 demonstrates the calculated resistivity for this sample (using Eq. 3). In this case the opposite to sample no. $226 \mathrm{~A}$ phenomenon is observed. If current is high enough $(1 \mathrm{~mA}$ and $0.5 \mathrm{~mA})$ then pores are blocking at the earlier time and IP effect occurs. The value of resistivity reaches $315 \mathrm{Ohmm}$. However decreasing current does not have an 
influence on the value of resistivity of sample ( $\sim 250 \mathrm{Ohmm})$. These laboratory measurements confirmed our theoretical consideration.

\subsection{Frequency}

The laboratory measurements and mathematical modeling (as example Fig. 7a time-on case and 7a - time-off) show that the process of membrane IP is relatively slow. Which is why there is no IP effect with high frequency of applied current: In fact the process of IP may not even have started during the short current cycle.

\subsection{Testing the theory with laboratory measurements}

Now we must reconcile the theory and laboratory measurements. Figure 18a, b, c demonstrate mathematical modeling of the IP effect for different applied currents, namely $0.5 \mathrm{~mA}$, $0.1 \mathrm{~mA}$ and $0.05 \mathrm{~mA}$ (time-on) and the subsequent diffusion process (time-off). These figures show calculated pores structure models for sample 226A. These figures demonstrate the possible size distribution of pores in the sample. The parameters of pores are shown in the Table 3, 22 cells of pores can roughly describe the pores structure of this sample.

Figure 19a presents a histogram of the relative volume of cylindrical shaped pores $V_{i} / V_{\Sigma}$ in the sample (where $V_{i}$ is the volume of all main pores of $i$-size and $V_{\Sigma}$ is the total volume of cylindrical shaped pores) vs. their volume. Obviously the large pores occupy more space but the number of these pores are relatively small (Table 3 ). The relationship between the relative amount of shaped pores and their volume is linear for this model (Fig. 19b). Another histogram (Fig. 19c) shows the relative amount of cylindrical shaped pores vs. their pore radius $r_{1}$. This is the first attempt to calculate the pore size distribution using IP laboratory data. Using different currents allow us to obtain more reliable data. However this approach must be continued and enhanced by further study. Agreement between the calculation results and laboratory data is good. Some differences at time-off for a large current can be explained by the limited numbers of pore cells especially of small scale.

We foresee a comparison between the pore size distribution obtained from the interpretation of laboratory measurements, and those obtained using neutron tomography which allows for the scanning of samples with a minimum spatial resolution of $100 \mu \mathrm{m}$ (De Beer et al., 2007).

\section{Conclusions}

Mathematical modeling of a little known model of IP referred to as "induced polarization caused by constrictivity of pores" was developed. Polarization occurs in all types of rocks if surface areas and transfer numbers are different for connected pores. The duration of the polarization process depends on two parameters: pore radii of connected capillaries and transfer numbers. During the polarization process all contacts between pores of different transfer numbers will be blocked and the electrical current will flow through the remaining canals. Two phenomena control the amplitude of potential difference at time-on: 1. Successive blockage of pores increases the resistivity of sediments and results in increased measured potential difference. 2. Excess concentration of electrolyte at the boundaries between pores with different radii provides an additional potential. The amplitude of the potential difference (voltage) of such rocks not only depends on solutions filling pore spaces, porosity and tourtuosity of pores channels, but also on ion mobility, diffusion coefficient, and difference of transfer numbers. During time-on a voltage is occurred due to flowing current $U_{\text {curr }}(t)$ and excess concentration $U_{\text {excess }}(t)$ at the contacts. However during the time-off only the excess of concentration $U_{\text {excess }}$ $(t)$ is involved in the diffusion process which intends to level the ion concentration along the pores. It was shown that measured chargeability is proportional to porosity. Blockage of pores and excess/loss ions at the contacted pores control this physical parameter. However the relationship between resistivity and porosity is very complicated. Mathematical modeling and laboratory measurements both confirmed the membrane IP effect diminishing with increasing salinity of fluid filled pores of rocks. The model of IP caused by constrictivity of pores can be regarded as a general model for membrane polarization. The new algorithm was tested on laboratory measurements data showing its good agreement with theory. The first attempt to calculate pore size distribution using IP laboratory data has been presented.

Membrane polarization does not exist on high frequency of electrical current. Which is why resistivity measured by direct and alternating current are different. The definition of the membrane IP effect is: "Membrane IP is the successive blockage of inter-pore connections due to the excess distribution of ions during current flow".

Acknowledgements. The author thanks M. E. Hauger for laboratory measurements and productive discussions.

Edited by: L. V. Eppelbaum

Reviewed by: three anonymous referees

\section{References}

Anderson, L. A. and Keller, G. V.: A study in induced polarization, Geophysics, 24(5), 848-864, 1964.

De beer, F., Zadorozhnaya, V., Middleton, M., and Schoeman, C.: Neutron imaging in South Africa adds value to geosciences and petrophysics, 19th geophysical conference and exhibition, Perth, Western Australia, 18-22, 2007.

Keller, G. V.: Analysis of some electrical transient measurements on igneous, sedimentary, and metamorphic rocks, Chap. 7, in: Overvoltage research and geophysical applications, edited by: Wait, J. R., 92-111, New York, Pergamon, Press, Inc., 1959. 
Keller, G. V. and Licastro, P. H.: Dielectric constant and electrical resistivity of natural state cores, US Geol. Survey Bull., 1052, 257-285, 1959 .

Jost, W.: Diffusion in Solids, Liquids, Gases: New York, Academic Press, Inc., 558 p., 1952.

Kobranova, V. N.: Petrophysics, Nedra, Moscow, 392 p., 1986, in Russian.

Koshlyakov, N. S., Gliner, E. B., and Smirnov, M. M.: Partial Differentiation of Equations in Mathematical Physics, Vysshaya shkola., Moscow, 710 p., 1970, in Russian.

Marshal, D. J. and Madden, T. R.: Induced Polarization, a Study of its cases, Geophysics, 24(4), 790-816, 1959.

Pipe, H., Riere, L., and Schopper, J. R.: Theory of semi-similar network structures in sedimentary and igneous rocks and their investigations with microscopical and physical methods, J. Microscopy, 2, 121-147, 1987.

Schön, J.: Physical Properties of Rocks. Fundamental and Principles of Petrophysics. Handbook of Geophysical Exploration. Seismic Exploration, Volume 18, New York, Pergamon, Press, Inc., 583 p., ISBN 008 0410081, 1996.
Titiov, K., Komarov, V., Tarasov, V., and Levitski, A.: Theoretical and experimental study of time domain-induced polarization in water saturated sands, J. Appl. Geophys., 50, 417-433, 2002.

Ward, S.: Resistivity and Induced Polarization Methods, in: Geotechnical and environmental geophysics, Investigation in Geophysics, No. 5, edited by: Ward, S., SEG, 169-189, 1990.

Zadorozhnaya, V. Y. and Hauger, M. E.: Membrane polarization on rocks and measured resistivity, in: Earth Elecrtomagnetic Investigations, edited by: Spichak, V. V., III International SchoolSeminar on Electromagnetic Sounding of the Earth (EMS-2007), Moscow, Russia, Lecture, 149-167, 2007.

Zadorozhnaya, V. Y. and Hauger, M. E.: Mathematic simulation of the membrane polarization occurring in rocks due to applied electrical current, Physics of the Solid Earth, in press, 2008a.

Zadorozhnaya V. Y. and Hauger, M. E.: Polarization processes in rocks and measured electrical resistivity, Geophysical Prospecting, in press, $2008 \mathrm{~b}$. 